Kgomotso H. Moahi

\title{
Globalization, Knowledge Economy and the implication for Indigenous Knowledge
}

\begin{abstract}
:
This paper considers the impact that globalization and the knowledge economy have on the protection and promotion of indigenous knowledge. It is asserted that globalization and the knowledge economy have opened up the world and facilitated the flow of information and knowledge. However, the flow of knowledge has been governed by uneven economic and political power between the developed countries and the developing countries. This has a number of ramifications for IK. The dilemma faced is that whichever method is taken to protect IK (IPR regimes, documenting IK etc) exposes IK to some misappropriation. Protecting it through IPR is also fraught with problems. Documenting IK exposes IK to the public domain and makes it that much easier to be misused. However, not protecting IK runs the danger of having it disappear as the custodians holding it die off, or as communities become swamped by the effects of globalization. The conclusion therefore is that governments have to take more interest in protecting, promoting and using IK than they have been doing.
\end{abstract}

\section{Agenda}

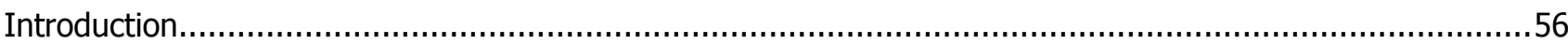

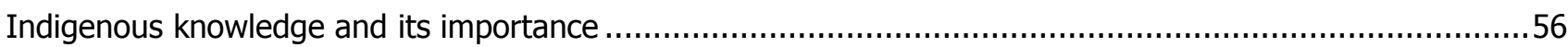

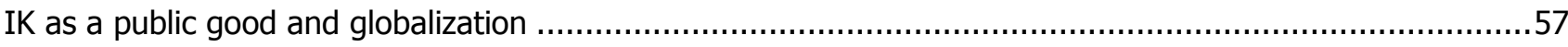

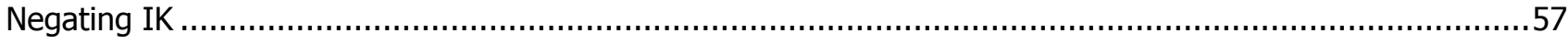

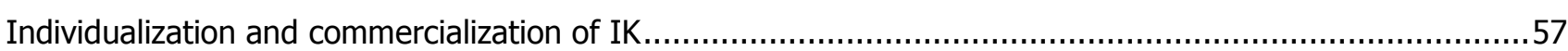

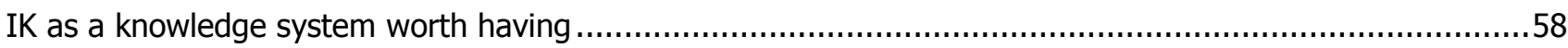

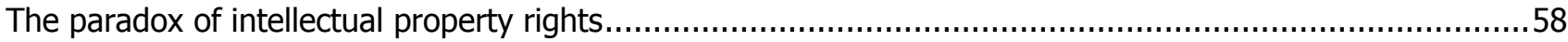

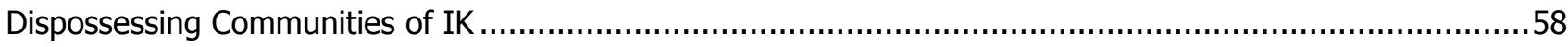

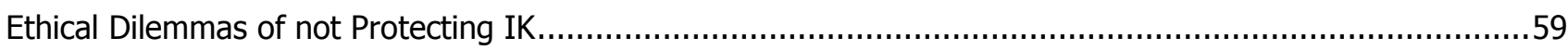

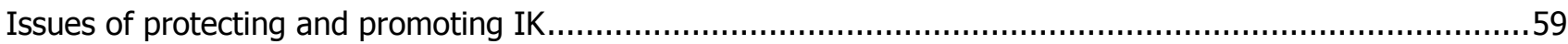

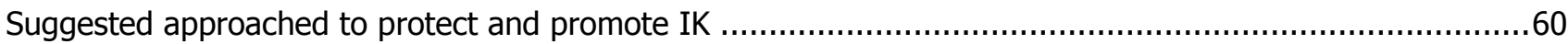

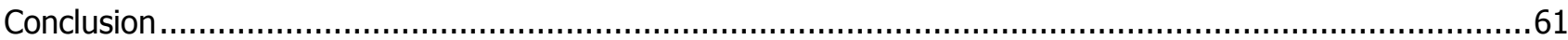

\section{Author:}

Dr. Kgomotso H. Moahi:

- University of Botswana Department of Library and Information Studie

- 正 +267 3552627, $\square$ Moahikh@mopipi.ub.bw 


\section{Introduction}

According to Mazrui, ${ }^{1}$ there are three distinct ways that globalization is interpreted: as economic interdependency across vast distances; information availability and movement across vast distances; and reduction of the world into a global village. Mazrui further states that 2 forms of globalization can be identified: economic globalization and cultural globalization. Globalization is also viewed as the opening up and interconnectedness of the world. This openness and interconnection has been given impetus by the need to open up economic and trade markets as well as developments in information and communication technologies culminating in the so called "knowledge economy". Many people assert that globalization is characterized by a mismatch of political and economic power, and that it is the more powerful countries in the north that benefit from globalization.

It has been stated in some quarters that colonialism can be viewed as the first stage of globalization. ${ }^{2}$ Mazrui agrees with this sentiment and states that although the term globalization is new, the actual process started centuries ago fueled by 4 major engines of religion, technology, economy and empire building. Colonialism was about empire building, finding raw materials and new markets ${ }^{3}$. To do this effectively, the colonizers used religion to undermine the rich cultures of the colonized people. At the same time, many people were displaced from their cultural lands to make ways for settlers and for development; cultural objects and artifacts were plundered and carried away from the colonized countries; indigenous knowledge of communities was at the same time denigrated as it was appropriated to create new products and ideas by the colonizers.

Misappropriation of indigenous knowledge and other products and artifacts is therefore not a new thing and has been going on for many centuries. It was only in the $20^{\text {th }}$ Century that issues of the intellectual property of communities from which the IK originates who were mostly in developing countries

\footnotetext{
1 Mazrui, Ali: Pan Africanism and the Origins of Globalization

${ }^{2}$ Saul, Samir: Colonialism.

3 Mazrui, Ali: PanAfricanism and the Origins of Globalization
}

was given any thought. These issues are still being debated and grappled with, and it is contended that globalization and the knowledge economy necessitates the protection and promotion of IK - a move that has ethical implications.

\section{Indigenous knowledge and its importance}

Many writers have defined indigenous knowledge as the knowledge, ideas and practices that are peculiar to a particular community and embody the community's identity and ways of surviving and maintaining the environment they find themselves in. Jones and Hunter maintain that there are varied meanings to indigenous knowledge and these emanate from the fact that IK itself is "embedded in the cultural fabric woven with the social, economic, technical, and scientific threads of a people developed and refined over time". ${ }^{4}$ However, some definitions of IK are based on the fact that it is derived from communities that are indigenous to a region or place. These may include the Maori of New Zealand, Basarwa of Botswana, American Indians and the indigenous people of Canada. But also, IK is often associated with rural based communities that possess limited or no education and who still live as one with nature, using IK to survive the vagrancies of nature. However, it is the contention that IK is not only a preserve of indigenous people or rural communities; IK is the knowledge that is held communally by communities that have lived in a particular area a significant amount of time. These communities may be indigenous, rural or urban. IK therefore represents a strategy that is used by communities to deal with everyday issues of life, be it food production, health, education, the environment, etc. Kiggundu distinguishes between indigenous knowledge and indigenous knowledge systems (IKS). He states that IK is also referred to as folklore; and IKS refers to the techniques and methods used by communities to harness the IK ${ }^{5}$.

Most IK, especially in developing countries, is not documented and is transmitted orally from generation to generation. As such, it is vulnerable to grad-

4 Jones, Michael \& Hunter, Joshua: Enshrining Indigenous Knowledge in the National Science Curriculum.

${ }^{5}$ Kiggundu, J. Intellectual Property Law and the Protection of Indigenous Knowledge. 
ual disappearance due to the influence of globalization and as individuals who lived life in the old way depart this life. Arguments have been raised that undocumented IK is considered to be in the public domain and therefore available for all with the possibility of being easily misappropriated. It is for these reasons that the documentation of IK has been advocated; the creation of digital libraries is seen as a way that ownership of IK can be articulated and the databases used to check whether the IK is new or has always existed and therefore cannot be patented to individuals wishing to own it.

The importance of IK has been acknowledged as crucial for health, agriculture and for commercial value in many other products. Arts and crafts emanating from indigenous knowledge have also attracted a lot of attention. The products of IK therefore are part of a multi million trade and investment in the world. Moahi, quoting Sahai notes that: "The global market for herbal products is exploding; it is estimated to touch 5 trillion by 2020 . Four out of ten people in the US are using what they call alternative medicine, even when the cost is not covered by medical insurance ${ }^{\prime \prime 6}$. The issue is that since such information is undocumented and is thus in the public domain, it has been used to produce goods and products from which the communities who own the IK have not benefited. It is for these reasons that people have advocated documentation to guard against the disappearance and misappropriation of IK. In spite of this interest and the money that is being made from IK, communities who own it are sliding further and further into poverty.

According to Daes ${ }^{7}$ IK is also a very important resource for communities because it is very much tied to the socio-economic, spiritual and cultural aspects of the owners' lives. He concludes therefore that the protection of IK cannot be divorced from rights to land, culture and to adequate livelihood for communities who own IK. At the same time IK is also important for the world as a whole, and should be shared as long as communities are consulted and acquiesce to its use and most importantly, benefit from such use.

6 Moahi, Kgomotso H: Documenting Indigenous Knowledge Systems: Prospects and Challenges

7 Daes, Erica-Irene: Some Observations and Current Developments on the Protection of the Intellectual Property of Indigenous People

\section{IK as a public good and globalization}

Economic globalization is characterized by transnational and multinational corporations seeking to extend their markets and sources of raw materials and ideas. Generally they tend to look for such in less developed countries. Indeed, Luna writes that there is a great rush to the world's forests to learn of the potential of medicinal plants ${ }^{8}$. This according to Mudiwa $^{9}$ is due to the fact that biological resources are the mainstay of man's survival and these are mostly found in developing countries. Although the contention is that biological resources are meant for the good of the entire world, the irony is that the finished products such as drugs are patented and are out of reach for poor countries and communities.

\section{Negating IK}

Cultural globalization can contribute to the erosion of people's languages and culture. This may have an effect on IK as the tendency is to be dismissive of undocumented, unscientific knowledge. Developments in media and information communication technologies contribute to this state of affairs. The effect has been to engender a negative attitude in most of the people towards all things indigenous, such as traditional practices relating to health, education, agriculture, etc. The major argument advanced is that such practices have no scientifically proven basis. Indigenous information is regarded as inferior and not backed and validated by scientific methods.

\section{Individualization and commercialization of IK}

Globalization has commoditized and privatized knowledge, resulting in the knowledge economy. Indigenous knowledge has not been exempt from this privatization. Knowledge that was in the public domain, owned by communities and passed down

${ }^{8}$ Luna, Jonathan: Bioprospecting or Biopiracy, the Complex Relations of the Appropriation of Indigenous Knowledge

${ }^{9}$ Mudiwa, Morries. Global Commons: the Case of Indigenous Knowledge, Intellectual Property Rights and Biodiversity 
from generation to generation, has been privatized by applying intellectual property rights that confer rights on individuals, effectively robbing whole communities. Daes states that globalization is a two edged sword: on the one hand it has opened up the world so that there is a free flow of ideas; whilst however, a few voices, and global corporations have drowned out other voices ${ }^{10}$. It is therefore not a surprise that IK is said to be under threat.

\section{IK as a knowledge system worth having}

Developments in information and communication technologies have fuelled what is now commonly referred to as the knowledge economy. The basis of this economy is that we live in a world where the major currency is information and knowledge just as much, if not more than capital and land. It is posited that whoever has access to information and knowledge and uses it effectively can expect to develop and generate wealth. A major argument is that developing nations are not progressing because they do not have access to knowledge that they would use to improve production and generate wealth. However, knowledge is available for use by developing countries, but it is not attractive because it is said to be unscientific, and can only be useful if subjected to the scientific methods which are mainly a western construct that the rest of the world adheres to. The development of information communication technologies has however, brought IK into focus as a knowledge system worth having - hence the clamor to obtain IK and develop products and services of value.

\section{The paradox of intellectual property rights}

The knowledge economy has had a number of influences and impact on indigenous knowledge and communities who own it. Thomas and Nyamnjoh ${ }^{11}$ have succinctly spelt out the ways in which both globalization and the knowledge economy have

${ }^{10}$ Daes, Erica-Irene: Some Observations and Current Developments on the Protection of the Intellectual Property of Indigenous People

${ }^{11}$ Thomas Pradip \& Nyamnjoh Francis: Intellectual Property Challenges in Africa: Indigenous Knowledge Systems and the Fate of Connected Worlds impacted IK. First, in the knowledge economy, intellectual property has been given a very high profile and represents greater economic value. Indeed, much of the intellectual property of knowledge products is not vested in those who created it, but rather in global corporations that become the content providers and therefore command the greatest profits. The efforts being made to apply intellectual property rights, which are by nature individualistic, to knowledge that is communally owned, such as IK, has created a myriad of problems, especially for the communities who own the IK. Thomas and Nyamnjoh further state that some elements of IK such as "music, weaves, symbols, artifacts, knowledge of natural resources, dance steps, motifs - are steadily becoming privatized and have become part of the circuits of knowledge production, distribution and consumption". ${ }^{12}$ The effect has been commercialization of these products with the result that they become trivialized and loose their sacredness and meaning. Indeed, as stated before, the communities whose baskets, etc are commercialized do not benefit to the extent that global capital does - women may weave baskets in Botswana, sell these to a middleman who conducts brisk trade in supplying some global partner who then makes much more money than the women will ever see from products of their own knowledge and hands. Thomas and Nyamnjoh state that as the knowledge economy spreads its tentacles, it begins to displace IK from the hands of its owners, the communities. The knowledge is then "reconfigured in response to the asking and dictates of global capital". ${ }^{13}$

\section{Dispossessing Communities of IK}

Globalization or neo-colonialism as some refer to it, has played a large role in dispossessing communities of their knowledge and identity. Many ideas and knowledge have been removed from communities through agreements for bilateral aid. Research organizations and governments in developing coun-

12 Thomas Pradip \& Nyamnjoh Francis: Intellectual Property Challenges in Africa: Indigenous Knowledge Systems and the Fate of Connected Worlds

${ }^{13}$ Thomas Pradip \& Nyamnjoh Francis: Intellectual Property Challenges in Africa: Indigenous Knowledge Systems and the Fate of Connected Worlds 
tries benefit from donor funding as long as they will accept foreign students and researchers to come and conduct research and invariably take home all the data and findings which eventually find their way back to developing countries as products developed in the West and patented there. Clearly there is dire need for intervention aimed at protecting IK and ensuring that the economic gains of communities and the protection of their sacred and confidential knowledge is assured.

\section{Ethical Dilemmas of not Protecting IK}

Despite the problems of protecting IK, there are however some ethical dilemmas of not protecting it and $\mathrm{Ng}^{\prime}$ etich $^{14}$ points them out clearly. Many communities that own documentation are slowly disappearing and their way of life is changing. It is therefore crucial that IK should be preserved through documentation. Second, although there are issues with Western technology through multinational corporations bankrolling the appropriation of IK, it is a fact that this technology is required as many communities do not have the means to facilitate the appropriation. Third, not documenting IK means that it is taken to be in the public domain to be picked up and used by anyone who has the means, documenting it means that there is a database against which patent claims can be checked. Fourth, knowledge and information have been shown to be the means to development and economic benefits, protecting IK secures IK for appropriation by the communities themselves through what Ruiz ${ }^{15}$ refers to as contracts and know-how licenses that regulate access to IK and establish terms under which such IK can be used as well as how communities should benefit.

\section{Issues of protecting and promoting IK}

According to writers such as Chisenga ${ }^{16}$ developing countries, especially Africa contributes a minimal amount of knowledge or content on the Internet. The Internet is completely dominated by the US, Europe and Asia. Such writers have insisted that these countries need to put their own indigenous information on the global network so that they not only look to foreign, westernized information to solve their problems, but also have access to their own. The argument is that such countries do have knowledge that is indigenous to their situation and therefore can assist them in surviving and generating wealth, and this information can be a means of bridging the knowledge divide that seems to exist. However, there are problems and issues to deal with.

First, is the failure of governments to harness IK even as they acknowledge that sustainable development can be abetted by integrating IK. There is talk of the importance of IK and the need to protect it, but governments have not done much, with a very few exceptions such as South Africa, India, Brazil, etc. The vacuum that is therefore created by the governments tends to be filled by other internationals organizations and researchers who may do so legally and illegally. Where international organizations provide support to efforts by government to harness and document IK, there are agreements that are made which provide access to external forces to the IK, sometimes without consultation of communities. ${ }^{17}$

Intellectual property rights agreements and conventions have been signed which according to owners of IK propose measures that run counter to the beliefs and cultures of the communities and tend to take a non-holistic approach that does not consider the rights of IK owners to land, biodiversity, and self determination, i.e. consider in situ IK protection: "Indigenous peoples have called for approaches for protection of rights over IK to be holistic, reflecting their holistic worldviews, where knowledge is inextricably linked to traditional territories, resources

${ }^{16}$ Chisenga, Justin: Indigenous Knowledge: Africa's Opportunity to contribute to Global Information Content

17 Thomas Pradip \& Nyamnjoh Francis: Intellectual Property Challenges in Africa: Indigenous Knowledge Systems and the Fate of Connected Worlds

${ }^{14} \mathrm{Ng}$ 'etich, Kibet A: Indigenous Knowledge, Alternative Medicine and Intellectual Property Rights Concerns in Kenya

${ }^{15}$ Ruiz, Manuel: Policy Briefs: National and Regional Laws to Protect IK related to Genetic Resources 
and culture". Also Swiderska \& Argumedo, ${ }^{18}$ reviewed a number (8) of UN agencies' activities in protection of IK. They found a common thread of weaknesses in the work of all these agencies that lend credence to the criticism leveled against these organizations by communities owning IK and other interested parties. These include creating an artificial boundary between IK, biodiversity and folklore and crafts; Treating IK in isolation from human rights of the communities that own IK, there is need for more recognition in this regard, and it has been missing; Membership is typically made up of government representatives, and communities are hardly represented and therefore are excluded from making decisions that affect them.

Second, there is reliance on Western science and technology to transform IK and products into value added products, and once this is done, communities tend to loose control of the product and not benefit from the profits that are made - and yet the knowledge originated from them. Also according to Kawoooya, African scholars, researchers and scientists are said to be reluctant to digitize IK because the very tools of the information society make it easy for such knowledge to be misappropriated. Others have argued that documenting IK, exposes it to the public when some communities would prefer to keep their own IK to themselves rather than expose it. Some communities may have own laws and regulations about what information may be disclosed and under what circumstances. This may be at variance with the establishment of national IK repositories or even IPR. Other arguments are that putting IK in the public stage may disadvantage communities that are rural and poor who may be unable to defend their knowledge and resources once they are out there from misappropriation.

Third, it is argued that IK can be protected by sui generis laws where the state legislates on behalf of the communities who own IK. Writers have expressed concern at this stating that it is undermining indigenous peoples' right to self determination and control of their own resources, and in some instances, may result $\mathrm{n}$ the exploitation and marginalization of such communities. Organizations such as WIPO and WTO advocate the use of existing or novel sui generis measures to protect IK. WIPO's Model Provisions for National Laws on the Protection of expressions of Folklore against Illicit exploitation

18 Swiderska, Krystyna \& Argumendo, Alejandro: Towards a Holistic Approach to Indigenous Knowledge Protection and other Prejudicial Actions provides a sui generis model for countries to adopt. ${ }^{19}$ In spite of this, few countries have sui generis protection, particularly in the African context.

Fourth it has been argued that access to the Internet will enable the developing countries to put their own content on to the Internet. However, Daes argues that for indigenous people, it will then be a struggle to keep their most sacred and private knowledge out of the Internet. "At the touch of the finger, volumes of confidential material will be placed irreversibly on the global public domain - the global commons-, where it can then be transformed and commercially exploited by others" ${ }^{20}$ Questions do arise: who will be responsible for putting content on the Internet? Will communities be able to access their own content? What powers will communities have to control access and use to that content? These are very real issues that must be addressed if IK is to come into its own and drive the development process.

\section{Suggested approached to protect and promote IK}

Given the weaknesses found in international efforts at protecting IK, there is a need for home grown solutions that will take into consideration the holistic rights of communities and involve them in policy making, decision making and implementation. At present, governments in the developing countries, particularly in Africa, have not expended their energies on the issue of protecting IK. If there are any activities, they are restricted to universities and research institutions without the participation of governments in devising policies and legislations governing bioprospecting, research and trade in IK, biodiversity and artifacts.

According to Moahi ${ }^{21}$, Governments can and should take more active interest in matters concerning IK.

${ }^{19}$ Kawooya, Dick: Copyright, Indigenous Knowledge and Africa's University Libraries: the Case of Uganda

20 Daes, Erica-Irene: Some Observations and Current Developments on the Protection of the Intellectual Property of Indigenous People

${ }^{21}$ Moahi, Kgomotso H: Documenting Indigenous Knowledge Systems in Africa: Prospects and Challenges 
They should do this by setting the national agenda through developing national IK policies and formulation of legislature that would protect and promote the use of IK for the national interest.

In taking an active position regarding IK, governments should do so in consultation with the various communities that own IK; there has to be collaboration and agreements on how, for example, sacred IK is to be treated; how communities must be consulted and play a active role in the protection, promotion and use of its IK, and in ensuring that IK protection is done in a holistic manner that takes into consideration all aspects of IK. In considering what should be done to protect and promote IK in Botswana, Kiggundu ${ }^{22}$ suggests the University of Botswana should take the lead and should therefore educate communities about indigenous knowledge rights. This would be a good approach and it is the contention here that governments should move to designate organizations to protect and promote IK, whilst at the same time educating communities about the importance of IK in IK rights.

Governments can also act by supporting and championing IK resource centers or repositories to act as clearinghouses for collecting, documenting and disseminating IK by sponsoring and encouraging research into IK in the same way that governments in South Africa, India, Brazil are doing. They can involve communities in IK documentation exercises to ensure that holistic documentation is maintained.

Another form of promoting and protecting IK is documenting IK in databases and websites to establish prior existence and deter fraudulent claims of IP. This should be done in consultation with communities where responsibility of putting IK in database is clearly articulated and access issues are taken into consideration and measures put in place to ensure proper use of the IK. According to Kiggundu ${ }^{23}$, once IK is documented in digital form it becomes easier to market it for the benefit of communities and to prevent what he terms "unauthorized and surreptitious exploitation". This has been done in countries such as India and Brazil.

${ }^{22}$ Kiggundu, J. University Education and Intellectual Property in the Digital Era: Whither Botswana?

${ }^{23}$ Kiggundu, J. University Education and Intellectual Property in the Digital Era: Whither Botswana? 2007
Government should also in consultation and collaboration with communities put in place sui generis legislation to govern the flow and use of IK in bid to protect it from misappropriation on the grounds that it cannot be patented because it does not have novelty value. This can be done by adding legislation within the existing laws that govern intellectual property rights. Kiggundu ${ }^{24}$ gives an example of how this may be done especially with regard to IK in areas of food, drinks and medicine. He states that such knowledge can be protected by geographic indications where patenting may not be possible.

\section{Conclusion}

This paper has shown how globalization and the knowledge economy has affected Indigenous Knowledge. Globalization and the knowledge economy have exposed IK for the potential and actual value it has yielded to the world's most powerful multinational corporations. At the same time too, globalization has negated IK by viewing it as untried and untested unless it is processed by Western technology. IK has also been individualized and commercialized to the point where symbols that are held sacred by communities are trivialized as slogans and logos that are used and patented. From the above, it is very clear that efforts must be expended to protect IK, if only to mitigate the above issues. This paper has considered a number of ways that have been used to protect IK: enacting sui generis laws; documenting IK; seeking contract licensing, etc. However, in order for the above to work, governments will have to take a more proactive stance and be at the forefront instead of background.

Despite the above, there are many initiatives in the developing world that are aimed at providing the much needed intervention to protect and promote IK in the face of globalizations. South Africa for example, has an IKS policy that was adopted in 2004 and supports research into IKS. Nigerians were recently urged by Obasanjo to set up a training and research institute in the field of traditional medicine. South Asian countries are poised to create a digital library of the region's traditional knowledge and develop laws against misappropriation. India has had its own traditional knowledge digital library which has been used as a benchmark by other countries.

${ }^{24}$ Kiggundu, J. Op Cit. (note 23 ) 


\section{References}

Armstrong, Chris \& Ford, Heather (2005). The African Digital Commons: A Participants' Guide 2005. Commons Sense Project, WITS University. $72 p p$.

Chisenga, Justin: Indigenous Knowledge: Africa's Opportunity to Contribute to Global Information Content. South African Journal of Libraries and information Science 68(1), 2002, p. 16-20.

Daes, Erica-Irene: Some Observations and Current Developments on the Protection of the Intellectual Property of Indigenous Peoples.

Jones, Michael, E \& Hunter Joshua: Enshrining Indigenous Knowledge in the National Science Curriculum: Issues Arising from the Maori Case. RCSD Conference- Chiang Mai University. July 11-24, 2003.

Kiggundu, J., Intellectual Property Law and the Protection of Indigenous Knowledge. In: Mazonde, I \& Thomas P. Indigenous Knowledge Systems and Intellectual Property in the Twenty-First Century Perspectives from Southern Africa. CODESRIA, University of Botswana and World Association for Christian Communication. 2007: pp. 26-47.

Kiggundu, J., University Education and Intellectual Property in the Digital Era: Wither Botswana?. Paper presented at an Intellectual Property Forum of the University of Botswana. April 2007: $17 p p$.

Luna, Jonathan: Bioprospecting or Biopiracy, the Complex Relations of the Appropriation of Indigenous Knowledge. Florida State University. DScholarship Repository. 2005: 56pp. at: http://dscholarship.lib.fsu.edu/undergrad/85 Accessed on 03/01/2007

Mazrui, Ali: Pan-Africanisim and the Origins of Globalization.

2001.

Http://igcs.binghamton.edu/igcs site/dirton12.h

tm Accessed on 03/01/2007

Moahi, Kgomotso H: Documenting Indigenous Knowledge systems in Africa: Prospects and Challenges. ESARBICA Journal Volume 24 (2005), pp.75-87.

Mudiwa, Morries: Global Commons: the Case of Indigenous Knowledge, Intellectual Property Rights and Biodiversity. Undated, 26pp.

Pradip, Thomas \& Nyamnjoh, Francis, B: Intellectual Property Challenges in Africa: Indigenous Knowledge Systems and the Fate of Connected Worlds. In: Mazonde, Isaac and Thomas, Pradip: Indigenous Knowledge Systems and Intellectual Property in the Twenty First Century.:
Perspectives from Southern Africa. CODESRIA, University of Botswana and World Association for Christian Communication. 2007: p. 12-25.

Ruiz, Manuel: Policy Briefs: National and Regional Laws to Protect IK Related to Genetic Resources. SciDev.Net.

Saul, Samir: Colonialism. University of Montreal. Undated

Swidersa, Kyrstyna \& Argumedo, Alejandro: Towards a Holistic Approach to Indigenous Knowledge Protection: UN Activities, 'Collective BioCultures Heritage' and the UNPFII. Fifth Session of the UN Permanent Forum on Indigenous Issues, 15-26 May 2006. N.Y. 